\title{
EDITORIAL
}

\section{FUNCTIONAL FOODS: CURRENT ISSUES AND TRENDS}

\author{
ALIMENTOS FUNCIONALES: ACTUALIDAD Y TENDENCIAS
}

Functional foods are characterized for containing various components, some of which are classified as nutrients, and they affect diverse important functions in the body producing wellness and health and/ or decrease in the risk of some diseases (1). Accordingly, these foods, besides from satisfying hunger and providing nutrients that are necessary for the organism, also prevent nutrition related diseases and improve the body at physical and mental levels $(2,3)$.

A global vision generated by trends in foods science recites that an alimentary product can be defined as a functional food if it has components with functions that are benefic, healthy or that prevent a disease and if said food accomplishes any of the following descriptions: a) is a natural food ; b) is a food to which a component has been added; c) is a food from which a component has been removed; d) is a food in which the nature of one or more of its components has been modified; e) is a food in which the bioavailability of one or more of its components has been modified or, $f$ ) any combination of the aforementioned possibilities (1).

Within the natural functional foods, it is worth mentioning the Mediterranean diet, which is acknowledged as a nutritional lifestyle strongly related to low mortality associated to diseases as obesity, cancer, neurodegenerative disorders and cardiovascular diseases (4). The Mediterranean diet is particularly important for comprising a wide variety of functional foods, which include fruits and vegetables, wine, spices, cereals, whole cereals, dietary fiber, dairy products, legumes, virgin olive oil, vegetable oils, fish, chicken and nuts, that contain bioactive compounds (polyphenols, carotenoids, phytosterols, fibers, peptides, mono and polyunsaturated fatty acids, among others) with biological activities as the antioxidant, protector against cancer and hypertension, and the improvement of the immune response, for which the benefic effects of this diet are derived from the interaction of almost all of the nutrients that conform it (4).

Currently, in modified functional foods, some active components are often used, such as: probiotics, oligosaccharides and dietary fiber (gastrointestinal tract control); eicosapentaenoic acid, EPA and docosahexaenoic acid, DHA (triglycerides reduction); chitosan, hydrolyzed soy protein (cholesterol reduction); peptides obtained from casein hydrolysis (blood pressure control); non-digestible dextrin, guava polyphenol (blood sugar level); palatinose, maltitol, erythritol and xylitol, tea polyphenol (dental care); casein phosphopeptide (minerals absorption) (5). New functional products recite functions in health, for instance: for fatigue, stress and sleep (theanine), vision (lutein), memory (Ginkgo biloba), joints (hydrolyzed collagen and glucosamine), blood flow and body temperature (Ginkgo biloba, heseretin) (5). 
Furthermore, the most active category of functional foods is the category of beverages, not only because they are products with great possibilities for adding bioactive components and nutrients to, and/or removal or reduction of undesired ingredients, but also because the growing interest of consumers in a healthy lifestyle has increased the demand for beverages that promote health and functional beverages that contain organic ingredients instead of artificial ingredients as colorants and added sugar (6). Despite functional beverages that contain catechins or polyphenols of green tea are popular for their healthy properties in the skin, for their antiaging effect and their antioxidant capability (7), the new trends point to "beauty beverages", which contain collagen and hydrolyzed collagen, and promise to improve the skin health (6).

PABLA MARÍA MÁRQUEZ FERNÁNDEZ Ingeniera Química, MSc. Facultad de Ciencias Farmacéuticas y Alimentarias, Universidad de Antioquia. Medellín, Colombia.

DIANA MARGARITA MÁRQUEZ FERNÁNDEZ Química Farmacéutica, MSc, PhD. Facultad de Ciencias Farmacéuticas y Alimentarias, Universidad de Antioquia. Medellín, Colombia.

\section{REFERENCES}

1. Roberfroid M. Part I. General issues with functional Food. En Saarela M, Functional Foods: Concept to Product. $2^{\text {nd }}$ Edition. Cambridge: Woodhead Publishing; 2011, 5-10 p.

2. Menrad K. Market and marketing of functional food in Europe. J Food Eng. 2003; 56:181-188.

3. Robertfroid MB. A European consensus of scientific concepts of functional foods. Nutrition 2000; 16: 689-691.

4. Ferraretto A, Perego S, Fiorilli, A. Mediterranean diet: functional foods and physical activity, benefits for human health. En Emerson D, Robinson A, Functional Foods : Sources, Biotechnology Applications, and Health Challenges. ${ }^{\text {th }}$ Edition. New York: Nova Science Publishers, Inc; 2013, 95-112 p.

5. Iwatani S, Yamamoto N. Functional food products in Japan: A review. FSHW. 2019. doi:https://doi.org/10.1016/j.fshw.2019.03.011

6. Nazir M, Arif S, Khan R S, Wahab N, Khalid N, Maqsood S. Opportunities and Challenges for Functional and Medicinal Beverages: Current and Future Trends. Trends Food Sci Technol. 2019. doi:https://doi.org/10.1016/j.tifs.2019.04.011

7. Paquin P. Functional and speciality beverage technology 2009. Cambridge: Woodhead Publishing Limited. 